\title{
Brain Gain for Thailand: The Determinants of International Students' Intention to Stay on after Graduation
}

\author{
Kanokwalee Kruanak and Athapol Ruangkanjanases
}

\begin{abstract}
Brain Gain is a phenomenon in which the destination country receives the human capital or a high level of skills and competence from other countries to replace the lost professionals. For Thailand, receiving talented foreign students and retain them for a period of time after their studies could probably reverse the situation from brain drain to brain gain. The objectives of this study were (1) to explore factors that influence foreign student intention to remain in Thailand after studies, (2) to propose the findings of this study to the national level.
\end{abstract}

Questionnaires dispersed among undergraduate and graduate foreign students studying in Thai universities which randomly selected.

Finally regression analysis were used on data in order to test all six hypothesizes of the study and the findings indicated that only three factors; students' life and study adjustment process, social support and career perception, were the significant predictors of the overall students' intention to remain in Thailand.

Furthermore, the results show a relationship between national economic development and inclination to stay or return.

Index Terms-Brain gain, factors, determinants, satisfaction, intension, stay on, international students, universities, graduation, Thailand.

\section{INTRODUCTION}

The international mobility of highly skilled, talented individual; human capital has been increasing substantially in the last decade in response to the expansion of the knowledge economy accompanying globalization. Considering the US as long immigration tradition and flexible labor markets, they widely open for the global citizens who are looking for the most promising places to live, to work, to earn money and to spend it [1]. The USA has, for a long time already, been recognized the benefits of capturing mobile skilled foreign professionals. The qualified education could be considered as the first door to attract the foreign students to study in the US. It's not only the selling US exports, but also for the future of the economy, this is the consequence of "Brain Gain".

From the viewpoint of developing countries (and transition economies) such as Thailand, the international mobility of

Manuscript received April 11, 2014; revised June 10, 2014.

Kanokwalee Kruanak is with the Chulalongkorn Business School, Chulalongkorn University, Thailand (e-mail kanokwalee.kr558@cbs.chula.ac.th). human capital produced effects of brain drain. In order to overcome the scarce of human capital and respond to the needs for national economic development, those countries have to prepare for global and national challenges [2] and act to remain quality human resources who could function well in the knowledge-based society.

In aspect of Thailand, it starts to improve the quality of higher education and seeks for drawing international students to the country. Thai government has been formulating policies in order to attract more foreign students, as there is a room for Thailand's opportunity for human capital gain in the future. The number of international students in Thailand has increased in each year. For the year 2010, Thailand hosted 20,155 international students at 103 higher education institutions. The overall totals of international students increased by $5.7 \%$ from the year 2009. The top sending countries, China (9,329), Laos (1,311) and Myanmar (1,310), comprised more than $59.29 \%$ of total international enrollments. Beyond these three countries, the international student enrollments were especially strong from Asia $(17,193)$ [3]. This group of students has potential to become highly skilled persons for Thailand if they intend to stay on and establish their careers after graduation. This is reasonable for the Thai government to develop their strategies of attracting and retaining talents in order to help the country change the situation from brain drain to brain gain and meet skills demand from overseas.

\section{LITERATURE REVIEW}

\section{A. The Theories of Reasoned Action and Planned Behavior}

The theory of reasoned action, which has its roots in social psychology, is "based on the assumption that human beings are usually quite rational and make systematic use of the information available to them and that people consider the implications of their actions before they decide to engage or not engage in a given behavior" [4]. While the theory of planned behavior describes the individual's level of behavioral control depends on his or her possession and causes the opportunity for performing that behavior. These theoretical frameworks explained discrepancies between mobility intention and behavior were suggested that behavioral outcomes best predicted by the intention to perform only when a behavior is under full volitional control.

The migration intention is a part of socio-demographic variables and results in behavioral inconsistencies. There are two issues on how the individual could lead migration 
intention to behavior. First, the complication of moving might be caused from the decision making based on the finalized agreement among household members. Second, mobility intention of the individual is shaped with his or her past experience. The study implies that a person will likely to have behavior repetition in the future once he or she had a good experience before, and are potentially to do so than an inexperienced one. In other words, those who had successful moving experience in the past are positive relatively to attitude and intention to move again. In addition, the theories of reasoned action and planned behavior in this regard for, understanding the process of migration decision making using social psychological theories of human behavior.

\section{B. Self-Selection Theory}

The self-selection theory was developed by Borjas [5], [6] to analyze the skills level of migrants. A key of his study is that a more unequal income distribution in the sending country will provide a negative impact on the skills mix of migrants in the host; negative self-selection [7]. A second prediction of Borjas' model is that the country which has a high inequality of income will potentially lead to lower emigration rates in that country; another negative self-selection. Those who satisfy below-average incomes in both receiving and hosting countries are also considered as negative self-selection. In the opposite way, the positive self-selection will happen when the earning distribution is greater available in the host country, while the source country collects higher taxes from highly skilled labor than less skilled ones. Therefore, the type of self-selection is not determined by the differences in incomes and migration cost, but they shape the size of migration flow.

\section{The Human Capital Theory of Migration}

The theory was initially introduced by Sjaastad [8] and then developed by Chiquiar and Hanson [9]. The result of negative-selection hypothesis test showed that those who have low skill level from poor countries with the greatest incentives will highly intend to migrate to rich countries.

\section{Self-Initiated Expatriation}

This paper provides a critical review on self-initiated expatriates (SIE) and the case study on the employment of migrants in Europe and France. The study indicated that "SIE" in this literature refers to individuals who have an international career experience. Unlike migrants, SIEs are referred to more in positive connotations, such being described as "accustomed to interacting and motivated to interact with host country nationals" [10]. The most self-initiated expatriation could be understood as a proactive decision to relocate internationally in order to maximize individual or family net advantages or fulfillment [11]. The most important reason for them to move aboard is country of origin and it is also the reason of whether to return or not.

The study also mentioned that most of SIEs who previously had international mobility experience in developed countries have high potentially to become permanent migrants in their new home countries. This is because they faced a relatively immigration process before. Significantly, to be successful in establishing career and then become a permanent labor in the host country, migrants have to navigate within the structural context in those countries in order to get through all barriers and achieve their career development.

\section{E. Protean Career}

The word "protean" adding to career was firstly applied in 1976 by Hall [12]. It described a career in person's aspect, not the organization, and involves a whole life perspective. The main objectives of this study are where the person's core values are driving his/her career decisions and where the main criteria of success. The literature defines the link between the protean concept and the context of growing organizational restructuring, decentralization and globalization.

Refer to Briscoe [13], individuals with protean career attitudes are self-directed, which means that they will target their own career values and follow the path to success. Those who have dynamic self-directed career, they will have high possibility to self-expatriate. Theoretically, a protean career attitude would reflect SIEs' fundamental, career-related attitudes that drive their entire career development process and expatriation experiences in general.

\section{F. Push-Pull Factors Influencing International Student Destination Choice}

According to Mazzarol and Soutar [14], Push-pull model describes the factors motivating international students in selection of a final study destination. And additional research examines the factors influencing choice of final host institution. Their finding is that the international student will choose the host destination is dependent on a variety of "pull" factors. This study provides the implications for government and education institutions seeking to recruit overseas students. The reasons that students would like to study aboard is to upgrade their economic and social status. Students from less developed countries likely head to more developed countries for their higher education. This is because the education system in the home country is weak and still limited than more advanced countries, which led to the significantly rise in the number of international students in overseas. Between the years 1960-1970, the growth rate of international student mobility globally was about 9 percents and around 6 percents from $1970-1980$. The global trend of international students could be implied to "push and pull" factors which drive students to study aboard.

\section{G. The International Policies of Brain Gain: A Review}

In countries where the bulk of research activity takes place in the industrial and business sectors, taxation and immigration issues viewed as critical factors in dealing with brain drain and brain gain. Due to the skill shortages, industrial and business sectors have to convince the national government to adjust immigration legislation in order to support the international mobility to their countries. Most governments have used the same solutions for similar problems, "introducing changes to their immigration regimes to facilitate and allow foreign trained highly skilled labor markets and fill existing or perceived gaps" [15]. However, the results and impact of these policies might be different in each country. There has been some variation across countries in the extent of flexibility and generosity introduced by these systems. 


\section{RESEARCH METHODOLOGY}

\section{A. Conceptual Framework}

The conceptual framework was based on the related studies and literature review. The model is presented a comprehensive perspective of the factors that influence the intention of foreign students to stay further in Thailand after graduates. The research model was developed from the factors influencing the decision to stay aboard model constructed by Y. Baruch et al. It comprises six variables, as independent variables, which were assumed that they have an impact on the international students' intention to stay aboard as a dependent variable. Fig. 1 showed the research model.

Based on the conceptual framework, the hypotheses of this study are hypothesized that:

Hypothesis 1: The adjustment level of foreign students in the host countries will have a positive relationship with the level of intention of whether to remain or not in the host countries. If the level of their adjustment is low, there is a high possibility that they will return to their home countries. But if the level of adjustment in the host countries is high, they will remain in the host countries. The adjustment processes are associated with the social support that the students receive. For example, Eisenberger [16] pointed out that organizational support play a vital role to employees' attitudes and their performance.

Hypothesis 2: The level of support that international students receive from their teachers, university, and friends at university in the host countries, the high level of support and assistance will influence their intention to stay in the host country.

Hypothesis 3: The strength of family or social ties that foreign students have with the people in the host countries will positively impact to the intention of foreign students to stay longer in the host countries after their graduation.

Hypothesis 4: The foreign students' perception towards the labor market of the host counties would affect their decision to stay on after completing studies. The prospects of searching for a job, the opportunity to get a job, the base salary they would receive comparing between their home and host countries. Also, the immigration policies of the host countries accommodate the establishment of international students. A strong labor market in the host countries will be positively associated with a foreign student's decision to not return to their home countries.

Hypothesis 5: Those international students, who have high level of Protean Career approach, will be associated with higher tendency to stay in the host countries. It means those who are in control of their careers and master their own career path will less influence by external pressure such as loyalty to their country of origin. Foreign students from strong emerging economies are likely to return their home and get a job at high position, while foreign students from less emerging countries will likely to stay in the host countries.

Hypothesis 6: The culture distance between host and home countries is another important factor for foreign student's decision making process. The culture theory at a national level Hofstede [17], Ronen \& Shenkar [18], Shenkar [19] suggests that there are a big culture gap between people coming from the Western and Far-East. Therefore, people from Western may be less inclined to stay in the Far-East countries. In other words, foreign students from strong economies are less likely to stay in the less developed countries.

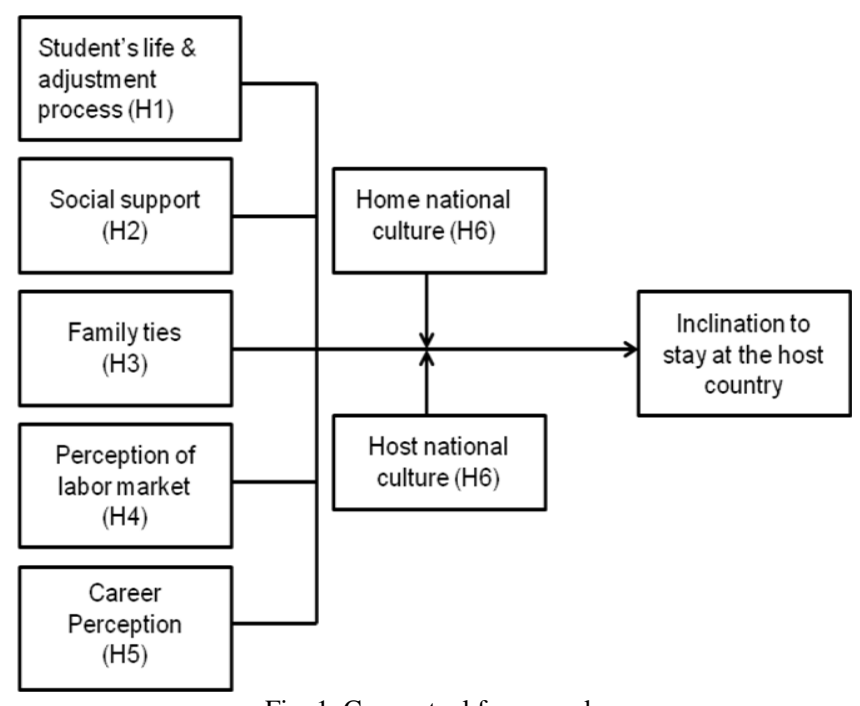

Fig. 1. Conceptual framework.

\section{B. Data Collection}

The primary data in this research is the questionnaire, which was created based on the several study reviews of literature books, articles, and related studies. The questionnaires were used to find out the factors influencing foreign students' intention to remain in Thailand when they graduate.

The questionnaire consists of five parts, which have main seventeen questions. The first part contains eleven questions which are descriptive information of the respondents. Then it followed by the questions in the second part asking the respondents' perceptions and attitudes toward Thailand. The third part presents six factors that lead to foreign students' decision of whether to stay or not in Thailand after graduation. For each question, a scale of five opinions were set from 1 (strongly disagree) to 5 (strongly agree). For the fourth part, the respondents will be asked to identify their intention to remain or not in Thailand with reason statements. The last one is for comments and suggestions from the respondents.

The secondary data for this paper, was developed from the literature review and related studies; self-initiated expatriation, protean career, push/pull strategy combine with the theory of reasoned action for immigration, brain drain and brain gain phenomenon, the human capital theory of migration.

A pilot study of 30 questionnaires was tested by thirty international students using Cronbach's Alpha; reliability test before sending out. The result was 0.919 , according to the reliability rule of George and Mallery [20]; the score was interpreted as excellent because the closer the coefficient is to 1.0, the greater is the internal consistency of the items (variables) in the scale.

Using 95 percent confidence level with sampling error of 5 percent based on Yamane [21], sample size of international 
students was 392.The researchers used the convenient sampling technique for data collection. Questionnaires were distributed to both public and private universities located in Bangkok and greater Bangkok. The survey was conducted between September and November 2013. Total of 236 completed questionnaires were returned. Therefore the sampling error of 7 percent was applied instead of 5 percent as originally planned.

\section{Measures}

This study was measured on a five-point Likert scale ranging from Strongly Disagree (1) to Strongly Agree (5),to measure the level of agreement of foreign students towards the provided statements. The measurement of student satisfaction was completed through a multi-structure. The respondents were asked to rate the level of their perceptions and attitudes toward Thailand, followed by rating the importance of all six variables which were assumed that they could influence their intention to stay further in Thailand after graduation. Likert survey was efficient method for data collection and could generate reflection on each factor which considered being significant to the overall student agreement.

\section{Independent Variables}

The independent variables consisted of six factors; students' life and study adjustment, social support, family ties, perception of labor market, career perception and cultural distance between home and host country. These all six factors were assumed that they would affect the international students' inclination to remain in Thailand.

Student's adjustment: was measured by examining the respondents' overall adjustment while studying in Thailand which all question statements were set based on the hypothesis one; "The adjustment level of foreign students in the host countries will have a positive relationship with the level of intention of whether to remain or not in the host countries."

Sample items for adjustment are 'I received considerable support in my adjustment', 'I am glad to have chosen University for my studies' and University provides a proper system and good educational environment for me. These statements were used to test the assumption that; if the level of their adjustment is low, there is a high possibility that they will return to their home countries. But if the level of adjustment in the host countries is high, they will remain in the host countries. The adjustment processes are associated with the social support that the students receive.

Social support: was measured by examining the social support the respondents received while studying in Thailand which all question statements were set based on the hypothesis two; "The level of support that international students receive from their teachers, university, and friends at university in the host countries, the high level of support and assistance will influence their intention to stay in the host country." Sample items are "My professor is considerate of my feelings', 'Students at University are friendly' and 'My fellow students are helpful in providing useful information and deepening the understanding about Thai society'.

Family ties: was measured by examining the impact of family ties towards the intention of respondents to stay in Thailand, which all question statements were set based on the hypothesis three; The strength of family or social ties that foreign students have with the people in the host countries will positively impact to the intention of foreign students to stay longer in the host countries after their graduation. Sample items are 'My family and I are very close', 'Living with my family is important to me' and 'My family supports my migration plan'.

Perception of labor market: was examined by measuring the respondents' perceptions of Thailand's labor market, which all question statements were set based on the hypothesis four; "A strong labor market in the host countries will be positively associated with a foreign student's decision to not return to their home countries." Examples of items are; 'There are a plenty of good jobs in Thailand', 'I have a lot of opportunity to get a good job', 'The salary is much better than I would receive in my home country' and 'The immigration policies of Thailand allows me to stay and work easily after graduation'. The prospects of searching for a job, the opportunity to get a job, the base salary they would receive comparing between their home and host countries. Also, the immigration policies of the host countries accommodate the establishment of international students.

Career perception: this matter was measured by examining aspects of career perception of respondents, which all question statements were set based on the hypothesis five; "Those international students, who have high level of Protean Career approach, will be associated with higher tendency to stay in the host countries." It means those who are in control of their careers and master their own career path will less influence by external pressure such as loyalty to their country of origin. Foreign students from strong emerging economies are likely to return their home and get a job at high position, while foreign students from less emerging countries will likely to stay in the host countries. Examples of items are; 'I believe that having international experience is essential for my subsequent career success', 'Choosing between two career options, I'll prefer the one I haven't tried yet' and 'I am the master of my own career path'.

Cultural distance between home and host country: was measured by examining the cultural distance between the respondents' home countries and Thailand, which all question statements were set based on the hypothesis six; ;"The culture distance between host and home countries is another important factors for foreign student's decision making process. There are a big culture gap between people coming from the Western and Far-East. Therefore, people from Western may be less inclined to stay in the Far-East countries. In other words, foreign students from strong economies are less likely to stay in the less developed countries. Sample items are; 'I feel closely connected to Thai people', 'My home have common beliefs with Thailand that might be easier to communicate and work with Thai people' and 'Country of origin background does not give negative effects to stay in Thailand'.

\section{E. Dependent Variable}

Overall student intention was the dependent variable of this study, which was assumed that all six independent variables are the cause. In this part, the logistic regression model was used to illustrate the analysis of binary data which the response could be only two possible values representing 
the presence and absence of foreign students' intention to stay further in Thailand after completing the study.

\section{DATA ANALYSIS}

Statistical Package for Social Sciences (SPSS) software was used in the analysis of primary data. Some of the descriptive statistics used include frequencies, means and percentages. The respondents were asked to provide their personal information, including gender, marital status, country of origin, education institution you are in, field of study, Level of study, overseas study experience outside the home country, years of stay in Thailand, work experience both inside and outside Thailand. The researchers assumed that some of these qualifications may have important effects on respondents' intention to whether remain or not in Thailand after completing studies (Fig. 2).

Other statistical analyses used to test the study's hypotheses in which the influential factors had positive effect on international students' intention to remain in Thailand after graduation. A series of Pearson's product correlation was applied to analyze the sample data in order to identify the relationships between six independent variables and the dependent variable. Multiple Regression analysis; was to be examined the predictive power of all six factors on the overall foreign students' intention to stay in Thailand. Cross tabulation analysis helped provide a way of analyzing and comparing the results for variables with the results of another.

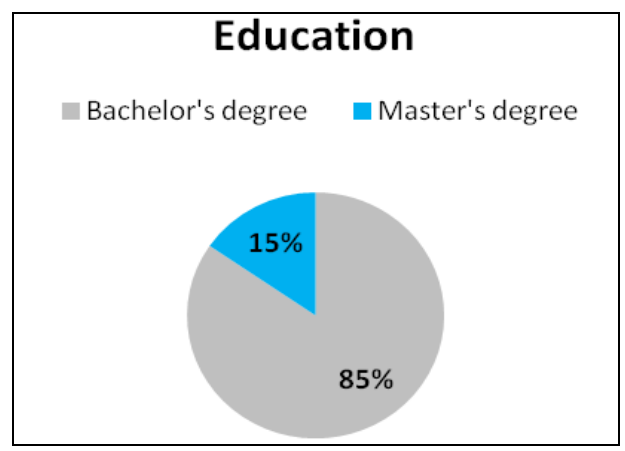

Fig. 2. Level of education.

\section{A. Part 1: Demographic Data of the Respondents}

Two hundred and thirty six international students took part in the study, the majority of respondents were female $(70 \%)$ which $90 \%$ were single, only $6 \%$ already married and $3 \%$ have been divorced. The majority of respondents were between the ages of 17 and 25 years old (71\%), followed by the age between 26 and 34 years old and between 35 and 43 years old respectively.

The country of origin varied: 158 students were from the developing countries (including 128 from China, 10 from Laos, 10 from Malaysia, 6 for India and 4 for Cambodia) while 50 students were from developed countries (including 36 from Japan, 12 from USA and 2 from Korea [22].

The highest numbers of respondents currently study at Thammasat University, which accounted for $43 \%$, followed by Huachiew University 31\%, Dhurakij Pundit University 7\%, Chulalongkorn 5\%, and Mahidol University 5\% respectively.

\begin{tabular}{lccc} 
TABLE I: FREQUENCY (NUMBERS) AND PERCENTAGE OF RESPONDENTS & \multicolumn{2}{c}{$\begin{array}{c}\text { ClASSIFIED BY PERSONAL FACTORS }(N=236) \\
\text { Frequency } \\
\text { Personal Factors }\end{array}$} & $\begin{array}{c}\text { Percentage } \\
(\boldsymbol{\%})\end{array}$ \\
\hline$\underline{\text { Gender }}$ & & 70 & 30 \\
& Male & & \\
& Female & 166 & 70 \\
\hline
\end{tabular}

\begin{tabular}{rcc}
\hline \multicolumn{1}{c}{ Age Range } \\
$17-25$ & 168 & 71 \\
$26-34$ & 62 & 26 \\
$35-43$ & 6 & 3 \\
\hline Marital Status & 212 & 90 \\
Single & 14 & 6 \\
Married & 8 & 3 \\
Divorced & 2 & 1 \\
Not specify & &
\end{tabular}

\begin{tabular}{|c|c|c|}
\hline \multicolumn{3}{|l|}{ Country of Origin } \\
\hline China & 128 & 54 \\
\hline India & 6 & 3 \\
\hline Japan & 36 & 15 \\
\hline Korea & 2 & 1 \\
\hline Laos & 10 & 4 \\
\hline Malaysia & 10 & 4 \\
\hline Myanmar & 2 & 1 \\
\hline USA & 12 & 5 \\
\hline Other & 26 & 11 \\
\hline \multicolumn{3}{|l|}{ University } \\
\hline Assumption University & 12 & 5 \\
\hline Chulalongkorn University & 12 & 5 \\
\hline Dhurakij Pundit University & 16 & 7 \\
\hline Mahidol University & 12 & 5 \\
\hline Ramkhamhaeng University & 2 & 1 \\
\hline Rangsit University & 4 & 2 \\
\hline Thammasat University & 102 & 43 \\
\hline Huachiew University & 74 & 31 \\
\hline Not specify & 2 & 1 \\
\hline
\end{tabular}

Field of Study

$\begin{array}{lcc}\text { Arts } & 12 & 5 \\ \text { Business Administration } & 36 & 15 \\ \text { Business English } & 6 & 3 \\ \text { IT Management } & 6 & 3 \\ \text { International Business } & 14 & 6 \\ \text { Management } & 4 & 2 \\ \text { Marketing } & 2 & 1 \\ \text { Thai for communication } & 22 & 9\end{array}$




\begin{tabular}{|c|c|c|}
\hline Thai language & 126 & 53 \\
\hline Tourism and hospitality & 2 & 1 \\
\hline Others & 4 & 2 \\
\hline Not specify & 2 & 1 \\
\hline \multicolumn{3}{|l|}{ Level of Study } \\
\hline Bachelor degree & 186 & 79 \\
\hline Master degree & 50 & 21 \\
\hline \multicolumn{3}{|c|}{ Overseas Study Experience } \\
\hline Yes & 70 & 30 \\
\hline No & 166 & 70 \\
\hline \multicolumn{3}{|l|}{ Years of Stay in Thailand } \\
\hline 1 years & 130 & 55 \\
\hline 2 years & 42 & 18 \\
\hline 3 years & 18 & 8 \\
\hline 4 years & 20 & 8 \\
\hline 5 years & 2 & 1 \\
\hline 6 years & 2 & 1 \\
\hline More than 6 years & 6 & 3 \\
\hline Less than 6 years & 12 & 5 \\
\hline Not specify & 4 & 2 \\
\hline \multicolumn{3}{|c|}{ Work Experience in Thailand } \\
\hline Yes & 24 & 10 \\
\hline No & 212 & 90 \\
\hline \multicolumn{3}{|c|}{ Years of Work in Thailand } \\
\hline 1 year & 6 & 38 \\
\hline 2 years & 4 & 25 \\
\hline 3 years & 3 & 4 \\
\hline 5 years & 2 & 13 \\
\hline \multicolumn{3}{|l|}{$\begin{array}{l}\text { Work Experience outside } \\
\text { Thailand }\end{array}$} \\
\hline Yes & 56 & 24 \\
\hline No & 180 & 76 \\
\hline \multicolumn{3}{|l|}{ Years of Work outside } \\
\hline \multicolumn{3}{|l|}{ Thailand } \\
\hline 1 year & 12 & 29 \\
\hline 2 years & 10 & 24 \\
\hline 3 years & 14 & 33 \\
\hline 4 years & 2 & 5 \\
\hline 6 years & 2 & 5 \\
\hline 16 years & 2 & 5 \\
\hline
\end{tabular}

The results indicated that the majority of respondents were Bachelor's students, which accounted for $79 \%$, followed by Master's students $14.4 \%$ of all respondents.

Responses of the field of study were ranging from $53 \%$ for Thai language major, followed by Business Administrator major $15 \%$, the third highest number of respondents $9 \%$ for Thai communication, $6 \%$ of respondents studying International Business major and very small number of respondents studied other majors such as Business English, IT Management, Management, Tourism and Hospitality respectively.

The findings showed that $70 \%$ of respondents had been studied overseas before coming to Thailand, While $55 \%$ of respondents has been staying in Thailand for one year, followed by 2 and 3 years respectively.

Moreover, $90 \%$ of respondents have never worked in Thailand, while $10 \%$ respondents have. And $24 \%$ of respondents had overseas experience before coming to Thailand, with the highest number $33 \%$ of respondents had been worked outside Thailand for 3 years and one- year work experience outside Thailand ranked the second. Further details are shown in Table I.

\section{B. Part 2: Perceptions and Attitudes towards Thailand}

The implications from the results are most respondents have a positive perception and attitude towards Thailand in aspects of the cost of living in Thailand (Mean $=3.81$ ), the quality of Thai University (Mean = 3.69), a fun place to study $($ Mean $=3.91)$ and the highest score was well-treated by Thai people (Mean=4.06). However the issue of Thailand's visa regulation for foreign stays was in neutral level (Mean=3.28).

More details are shown in Table II.

TABLE II: SUMMARY OF RESPONDENTS’ AGREEMENT ON PERCEPTIONS AND ATTITUDES TOWARDS THAILAND $(N=236)$

\begin{tabular}{lll}
\hline \hline \multicolumn{1}{c}{ Variables } & Mean & Meaning \\
\hline $\begin{array}{l}\text { I am satisfied with the cost of living in } \\
\text { Thailand }\end{array}$ & 3.81 & Agree \\
$\begin{array}{l}\text { I am satisfied with the quality of Thai } \\
\text { University }\end{array}$ & 3.69 & Agree \\
$\begin{array}{l}\text { I think Thailand is a fun place to study } \\
\begin{array}{l}\text { I am satisfied with Thailand's visa regulation } \\
\text { for foreign stays }\end{array}\end{array}$ & 3.28 & Agree \\
$\begin{array}{l}\text { I am treated well by Thai people while } \\
\text { staying in Thailand }\end{array}$ & 4.06 & Agree \\
$\begin{array}{l}\text { Overall perceptions and attitudes towards } \\
\text { Thailand (Average score) }\end{array}$ & $\mathbf{3 . 7 5}$ & Agree \\
\hline \hline
\end{tabular}

\section{Part 3: Summary of Descriptive Statistics of All Variables}

Within each variable, a set of related statements will be presents for respondents to indicate their level of agreement, ranging from (1) strongly disagree to (5) strongly agree.

\begin{tabular}{lll}
\multicolumn{3}{c}{ TABLE III: SUMMARY OF DESCRIPTIVE STATISTICS $(N=236)$} \\
\hline \hline \multicolumn{1}{c}{ Variables } & Mean & Meaning \\
\hline Social Support & 3.90 & Agree \\
Family Ties & 3.86 & Agree \\
Career Perception & 3.73 & Agree \\
Student's life and adjustment process & 3.62 & Agree \\
cultural distance between home and & 3.54 & Agree \\
host country & & \\
Perception of Labor Market & 3.41 & Agree \\
Overall Agreement (Average score) & $\mathbf{3 . 7 5}$ & Agree
\end{tabular}

Results derived from the questionnaires showed that the overall trend of agreement level towards the influencing factors of foreign students' intention to remain in Thailand after graduation was in "agree" level. Table III showed that every variable was in agree level, the factor that had the highest overall agreement level was social support $($ Mean $=$ 
$3.9)$, the second highest was family ties factors (Mean = 3.86 ), followed by the factor of career perception (Mean = 3.73 ), students' life and study adjustment process (Mean = 3.62 ), cultural distance between home and host country (Mean $=3.54)$ and the lowest was perception of labor market (Mean $=3.41)$.

\section{Part 4: Analysis of Factors Influencing Foreign} Students' Intention to Remain in Thailand after Graduation

The purpose for this part is to analyze six factors whether each of them could influence the international students' intention to remain in Thailand after graduates. The six hypotheses were tested and concluded as follows;

\section{1) Step-wise multiple regression analysis}

The overall students' intention to stay was defined as criterion or dependent variable. When stepwise multiple regressions was applied, the result revealed that from total six variables, only three independent variables were reported to be the significant predictors of the overall students' intention to stay. These three factors were: students' life and study adjustment, social support and career perception. The multiple regression model was illustrated in Fig. 3.

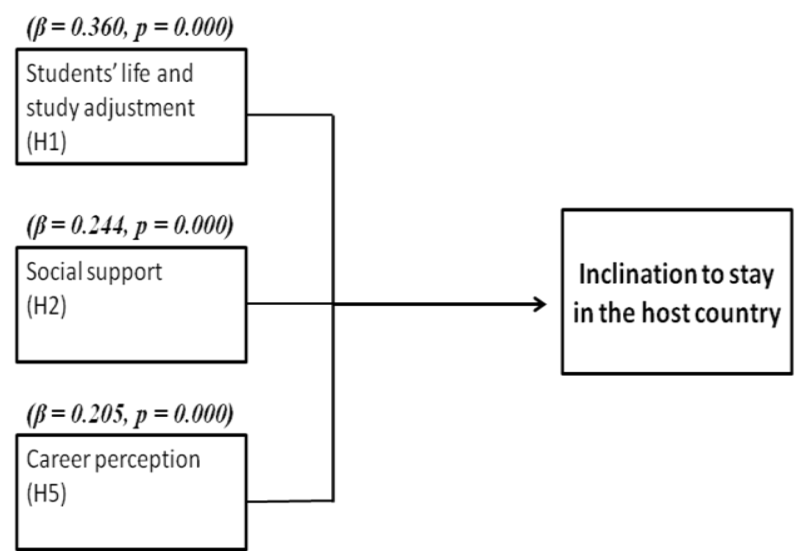

Fig. 3. Multiple regressions model.

They could be explained that $42.6 \%$ of the variance of the dependent variable, (adjusted $R^{2}=0.426$ ) with the significance level ( $p$-value) at 0.000 . By being less than 0.01 alpha levels, were referred by the researcher. The $\mathrm{p}$-value of 0.000 is statistically significant at $99 \%$ confident level. The highest positive relationship factor with the overall foreign students' intention to stay in Thailand influenced by students' life and study adjustment has the largest Beta coefficient with $0.360(p=0.000)$, followed by social support $(\beta=0.244, p=0.000)$, career perception $(\beta=0.205, p=$ 0.000 , and keeping all other variables constant. These data run with $99 \%$ confident level instead of $95 \%$ and found these three factors; students' life and study adjustment, social support and career were statistically significant at $99 \%$ confident level. More details are shown in Table IV.

\section{2) Correlation analysis}

For hypothesis testing, Pearson's product moment correlation was performed. The correlation analysis showed the direction of the relationship, as well as, its magnitude. Regarding to the study, results disclosed that the independent variables (all six factors) had significant positive relationship with the dependent variable (overall student intention), ranged from $r=0.182$ to $r=0.587$ and were significant at 0.000 level.

To be descriptive, the factor that has the highest positive relationship with overall students' intention to stay was students' life and study adjustment ( $r=0.587, p=0.000)$, followed by social support $(r=0.540, p=0.000)$, career perception ( $r=0.442, p=0.000)$, cultural distance between home and host country $(r=0.423, p=0.000)$, family ties $(r=$ $0.394, p=0.000)$, and the lowest positive relationship was perception of labor market $(r=0.182, p=0.000)$. Hence, the Hypothesis 1 to 6 was asserted. More details are shown in Table V.

\section{3) Intention to remain in Thailand}

In this section, the focus is on the intentions to remain in Thailand of international students studying in undergraduate and graduate level in Thai Universities situated in Bangkok and greater Bangkok. As the previous section, the mean scores were in "agreement"; thus the results of remain intentions of international students must follow. In this part, the logistics regression was used to illustrate the analysis of binary data which the response could be only two possible values representing the presence and absence of foreign students' intention to stay further in Thailand after completing the study. Table VI showed the results. For convenience, the values were coded as one or zero as

$$
\begin{aligned}
& =1 \text { if the student has intention to continue their } \\
& y\} \begin{array}{l}
\text { Stay in Thailand } \\
=0 \text { otherwise }
\end{array}
\end{aligned}
$$

Table VI showed that most respondents decided to not remain in Thailand, with the amount of 178 (75\%) respondents, while $58(25 \%)$ respondents had an absolute intention to stay in Thailand after finished their degree.

\section{4) Cross tabulation analysis}

Cross tabulation analysis helped provide a way of analyzing and comparing the results for variables with the results of another. In this case, the analysis based on two categories; the students' geographic location and level of study between the three significant factors; students' life and study adjustment, social support and career perception of foreign students.

Table VII showed that 50 students came from developed countries while 160 students came from developing countries. $76 \%$ of total students from developed countries decided to not remain in Thailand after graduates, only $24 \%$ of respondents were willing to stay on. Total of $22 \%$ of students who came from developing countries have planned to stay further in Thailand, while $78 \%$ of that group intended to leave Thailand after completion their study.

Furthermore, the category of study level of students was used to the analysis in order to compare between foreign students from developed and developing countries towards the intention to remain in Thailand.

Table VIII showed that $150(81 \%)$ Bachelor students did not intend to remain in Thailand after graduation while 36 (19\%) intended to stay on. Total of $28(56 \%)$ graduate students intended to leave Thailand, while 22 (44\%) had a certain intention to stay on after finished a degree. 
TABLE IV: SUMMARY RESULT OF MULTIPLE REGRESSION ANALYSIS AMONG VARIABLES ( $N=236$ )

\begin{tabular}{|c|c|c|c|c|c|c|c|c|}
\hline & Variables & B & $\beta$ & $t$ & $R$ & $R^{2}$ & $R^{2} a d j$ & Overall F \\
\hline \multicolumn{5}{|c|}{ Criterion: Overall Satisfaction } & .658 & .433 & .426 & $59.157 * * *$ \\
\hline \multirow[t]{3}{*}{ Predictor: } & 1. Students' life and study adjustment & .306 & .360 & $5.691 * * *$ & & & & \\
\hline & 2. Social support & .206 & .244 & $3.862 * * *$ & & & & \\
\hline & 3. Career perception & .192 & .205 & $3.720 * * *$ & & & & \\
\hline
\end{tabular}

Note: Significance level: $* * p<0.05, * * * p<0.01$

TABLE V: SUMMARY OF CORRELATION AMONG SIX VARIABLES $(N=236)$

\begin{tabular}{|c|c|c|c|c|c|c|c|}
\hline Variables & $\begin{array}{l}\text { Students' life } \\
\text { and study } \\
\text { adjustment }\end{array}$ & $\begin{array}{l}\text { Social } \\
\text { support }\end{array}$ & $\begin{array}{l}\text { Family } \\
\text { Ties }\end{array}$ & $\begin{array}{l}\text { Perception of } \\
\text { labor market }\end{array}$ & $\begin{array}{c}\text { Career } \\
\text { perception }\end{array}$ & $\begin{array}{c}\text { Cultural } \\
\text { distance } \\
\text { between home } \\
\text { and host } \\
\text { country }\end{array}$ & Overall Intention \\
\hline $\begin{array}{l}\text { Students' life and study } \\
\text { adjustment }\end{array}$ & & $.600^{* *}$ & $.337^{* *}$ & $.361^{* * *}$ & $.393^{* *}$ & $.475^{* *}$ & $.587^{* *}$ \\
\hline Social support & & & $.386^{* *}$ & $.320^{* *}$ & $.391^{* *}$ & $.520^{* *}$ & $.540^{* *}$ \\
\hline Family Ties & & & & $.409^{* *}$ & $.550^{* *}$ & $.485^{* *}$ & $.394^{* *}$ \\
\hline Perception of labor market & & & & & $.489^{* *}$ & $.576^{* *}$ & $.182^{* *}$ \\
\hline Career perception & & & & & & $.598^{* *}$ & $.442^{* *}$ \\
\hline $\begin{array}{l}\text { Cultural distance between } \\
\text { home and host country }\end{array}$ & & & & & & & $.423^{* *}$ \\
\hline Overall Intention & & & & & & & \\
\hline
\end{tabular}

TABLE VI: FOREIGN STUDENTS’ INTENTION TO REMAIN IN THAILAND AND RETURN THEIR HOME COUNTRIES

\begin{tabular}{lll}
\hline \hline Variables & Mean & Meaning \\
\hline Definitely yes & 58 & $25 \%$ \\
Definitely not & 178 & $75 \%$ \\
\hline Total & 236 & 100 \\
\hline \hline
\end{tabular}

TABLE VII: FOREIGN STUDENTS' INTENTION TO REMAIN IN THAILAND AND RETURN THEIR HOME COUNTRIES (CATEGORIZED BY COUNTRY GROUP)

\begin{tabular}{ccccc}
\hline \multirow{2}{*}{ Variables } & \multicolumn{4}{c}{ OECD Country Group } \\
& Developed Countries & Developing Countries \\
\cline { 2 - 5 } & Frequency & Percentage & Frequency & Percentage \\
\hline $\begin{array}{c}\text { DEFINITELY } \\
\text { YES } \\
\text { Definitely } \\
\text { not }\end{array}$ & 12 & 24 & 36 & 22 \\
\hline Total & 38 & 76 & 124 & 78 \\
\hline \hline
\end{tabular}

TABLE VIII: FOREIGN STUDENTS' INTENTION TO REMAIN IN THAILAND AND RETURN THEIR HOME COUNTRIES (CATEGORIZED BY LEVEL OF STUDY) Level of Study

\begin{tabular}{ccccc} 
& \multicolumn{2}{c}{ Undergraduate } & \multicolumn{2}{c}{ Graduate } \\
\cline { 2 - 5 } Variables & Frequency & Percentage & Frequency & Percentage \\
\hline $\begin{array}{c}\text { Definitely } \\
\text { yes } \\
\text { Definitely not }\end{array}$ & 36 & 19 & 22 & 44 \\
\hline Total & 150 & 81 & 28 & 56 \\
\hline \hline
\end{tabular}

\section{CONCLUSION AND DISCUSSION}

The study found support for the proposed hypotheses. The foreign students' life and study adjustment process was found as the most significant predictor of the intention of foreign students to stay in the host country (Hypothesis 1.) This will be associated with Baruchetal [23] found from a survey among students who come to study in the UK and the U.S, that whether the foreign students to stay in the host country or return to the home country depends on the level of adjustment in the host country.

There are many challenges facing foreign students when go to study aboard if the culture between home and host country are different. The study of Ward, Bochner and Furnham [24] suggested that well-being of students, as well as their academic performance, could be affected by these adjustment challenges. In addition, Adler [25],Ward, Okura, Kennedy \& Kojima [26], and Ward \& Rana-Dueba [27] found that whether foreign students to lengthen their stay or not is caused by the process of adjustment, for example, foreign students with discomfort usually reducing when they become more familiar.

Similarly, the level of support that international students receive from their teachers, university, and friends at Thai University was the second most significant predictor that will encourage foreign students to stay longer in the Thailand (Hypothesis 2). The student's well being in the receiving country, were usually sponsored by the family and the strong relationship with their associates. The greater received support, the greater intention to remain in the host country after complete their studies. As mentioned above, it also fits well with Tung's [28] models of acculturation of expatriates. The findings from this study, career perception of respondents is the another significant predictor of the intention to stay of foreign students in Thailand after graduation (Hypothesis 6). Career conception in this term means protean career-which are in control of their career [12] will tend to be their own career master and inclined to follow their plan. And those who have high protean career may flourish in a boundary less career environment, which exists within international assignment [28]. Refer to [13], individuals with protean career attitudes are self-directed, which means that they will target their own career values and 
follow the path to success. According to Inkson [29] and Suutari and Brewster [30], those who have dynamic self-directed career will have high possibility to self-expatriate. Theoretically, a protean career attitude would reflect SIEs' fundamental, career-related attitudes that drive their entire career development process and expatriation experiences in general.

\section{RECOMMENDATION}

After the analysis and the final conclusion were made based on the results from foreign students who are studying in Thai Universities as the target group, the study found that there are a greater number of students (160) from developing countries than those who came from the developed ones (76) studying in Thailand. Thus, Thailand also needs to be conscious of the fact that it is gradually becoming a receiving country and has the potential to enhance and take advantage of this. The findings of this study would be useful at both institutional and national levels. Thailand can learn from Singapore, which is another interesting example in that it is a receiving country and initiated a policy of encouraging skilled migration from developed countries to fulfill the skilled labor shortage in temporary term, rather than permanent migration.

In terms of Thailand, what to concern is that the education in Thailand's neighboring countries remains limited, it means that Thailand can expect a greater influx of students from Burma, Laos, Cambodia and Vietnam as recommended as following; creating the suitable environment for foreign students is to reverse the brain drain to brain gain. The suggestions from the respondents could be helpful for developing the strategies, for example, improving the VISA process and extend VISA duration to facilitate the foreign students' living in Thailand and International program in Thai Universities should provide the real international environment. Moreover, creating the easy working environment may attract a number of these students to stay longer in Thailand. With this way, it will increase the human capital for Thailand.

Furthermore, Thailand should strengthen its position itself as an international educational center for the ASEAN Region as follows;

1) The government should solve the political problems and try to have the political stability to entrust the foreign students that Thailand is a safe place to study.

2) Thailand's Higher Education Institutions both public and private should offer many levels of international programs for Bachelor's and Master's Degree as well as Doctoral to offer a choice of study for foreign students such as business management, economics, social sciences, engineering, medicine and nursing.

Improvement of the quality of academic and research institutes, as well as, the quality of the working environment are important issues.

\section{LIMITATION OF THE STUDY}

As the time constraints in this study, so other factors had not been examined on the foreign student's intention to remain in Thailand after graduation. Another limitation is that the result of study focused on the specific population while they represented the whole foreign students in Thailand. This is because the researchers used the convenient sampling technique for questionnaires distribution. Further, nearly $55 \%$ of respondents were Chinese; therefore, the study does not speak for total international students. Moreover, because of time constraint, only 236 completed questionnaires were returned by the end of survey period. Consequently, the researchers had to apply $7 \%$ instead of $5 \%$ sampling error.

\section{FUTURE RESEARCH}

Since this study only focused on the advantage of the intention to remain in Thailand of foreign students, but did not mention about the effect of their validity in Thailand, it could provide the negative effect to employment of Thai graduates. Therefore, the future study should present both sides of the availability of foreign students in Thailand.

Moreover, this study does not construct a panel dataset to follow the actual migration behavior of the student, so the researchers are unable to capture variation over time and cannot provide the evidence of whether the foreign student will change the plan of remaining or not after completing his/her study.

\section{REFERENCES}

[1] T. Straubhaar, "International mobility of the highly skilled: Brain gain, brain drain or brain exchange," HWWA Discussion Paper, no. 88, p. 8, 2000 .

[2] C. T. Chang, "Internationalization development of Thailand's higher education: Positioning Thailand as an international education center of the ASEAN region," Sripatum International College's Country Report, 2011.

[3] Foreign Students in Thai Higher Education Institutions 2010, 2011. Office of the Higher Education Commission, Bureau of International Cooperation Strategy, Ministry of Education. [Online]. Available: http://www.inter.mua.go.th/main2/article.php?id=201

[4] I. Ajzen and M. Fishbein, Understanding Attitudes and Predicting Social Behavior, Englewood Cliffs, NJ: Prentice-Hall, p. 5, 1980.

[5] G. J. Borjas, "Self-Selection and the Earnings of Immigrants," Journal of Labour Economics, vol. 3, no. 4, pp. 463-489, 1987.

[6] G. J. Borjas, "The Economics of Immigrant," Journal of Economic Perspective, vol. 9, no. 2, pp. 3-22, 1994.

[7] T. Liebig and A. Sousa-Poza, "How does income inequality influence international migration?" ERSA Conference Papers, vol. 3, p. 472, 2003.

[8] L. A. Sjaastad, "The costs and returns of human migration," Journal of Political Economy, vol. 70, pp. 80-93, 1962.

[9] D. Chiquiar and G. Hanson, "International migration, self-selection, and the distribution of wages: evidence from Mexico and the United States," Journal of Political Economy, vol. 113, no. 2, pp. 239-281, 2005.

[10] V. Peltokorpi and F. J. Froese, "Organizational expatriates and self-initiated expatriates: Who adjusts better to work and life in Japan?" International Journal of Human Resource Management, vol. 20, no. 5 , pp. 1095-1111, 2009

[11] A. Al Ariss, "Understanding self-initiated expatriates: Career experiences of lebanese self-initiated expatriates," Thunderbird International Business Review, vol. 52, no. 4, pp. 275-285, 2010.

[12] D. T. Hall, "The protean career: A quarter-century journey," Journal of Vocational Behavior, vol. 65, no. 1, pp. 1-13, 2004.

[13] J. P. Briscoe, D. T. Hall, and R. L. F. DeMuth, "Protean and boundaryless careers: An empirical exploration," Journal of Vocational Behavior, vol. 69, pp. 30-47, 2006.

[14] T. Mazzarol and G. N. Soutar, "'Push-pull' factors influencing international students destination choice," International Journal of Education Management, vol. 16, no. 2, pp. 82-90, 2002. 
[15] S. Mahroum, "Brain gain, brain drain: an international overview," in Proc. Austrian Ministry for Transport, Innovation and Technology Seminar, Alpbach, Austria, 2003, pp. 22-23.

[16] R. Eisenberger, P. M. Rasolo, and V. Davis-LaMastro, "Effects of perceived organizational support on employee diligence, innovation, and commitment," Journal of Applied Psychology, vol. 53, pp. 51-59, 1990.

[17] G. Hofstede, Culture's Consequences: International Differences in Work Related Values, Beverly Hill, CA, Sage, 1980.

[18] S. Ronen and O. Shenkar, "Clustering countries on attitudinal dimensions: A review and synthesis," Academy of Management Review, vol. 10, pp. 435-454, 1985.

[19] O. Shenkar, "Cultural distance revisited: Towards a more rigorous conceptualization and measurement of cultural differences," Journal of International Business Studies, vol. 32, pp. 519-535, 2001.

[20] D. George and P. Mallery, SPSS for Windows Step by Step: A Simple Guide and Reference, $4^{\text {th }}$ ed. Boston: Allyn \& Bacon, 2003.

[21] T. Yamane, Statistics, an Introductory Analysis, $2^{\text {nd }}$ ed. New York: Harper and Row, 1967.

[22] The World Bank Group. (2013). World Bank list of economies, October 2013. [Online]. Available: http://siteresources.worldbank.org/ DATA STATISTICS/Resources/CLASS.XLS

[23] Y. Baruch, S. P. Budhwar, and Kathrin, "Brain drain: Inclination to stay abroad after studies," Journal of World Business, vol. 42, pp. 99-112, 2007.

[24] S. Bochner and A. Furnham, The Psychology of Culture Shock, $2^{\text {nd }}$ ed. Routledge, 2001.

[25] F. Adler, Sisters in Crime: The Rise of the New Female Criminal, New York: McGraw-Hill, 1975.
[26] C. Ward, S. Bochner, and A. Furnham, The Psychology of Cultural Shock, Philadelphia: Routledge, 2001.

[27] C. Ward and R. Rana-Deuba, "Acculturation and adaptation revisited," Journal of Cross-Cultural Psychology, vol. 30, pp. 422-442, 1999.

[28] R. L. Tung, "American expatriates abroad: From Neophytes to cosmopolitans," Journal of World Business, vol. 33, no. 2, pp. 125-144, 1998.

[29] K. Inkson, M. B. Arthur, J. K. Pringle, and S. Barry, "Expatriate assignment versus overseas experience: contrasting models of human resource development," Journal of World Business, vol. 32, no. 4, pp. 351-368, 1997.

[30] V. Suutari and C. Brewster, "Making their own way: International experience through self-directed foreign assignments," Journal of World Business, vol. 35, no. 4, pp. 417-431, 2000.

Kanokwalee Kruanak graduated with a bachelor's degree in political sciences. Her major is international affairs in Thammasat University with first-class honors. Currently, she is working in public company specializes building construction business. Besides working full-time, she enrolled further her study for master's degree in master of management program of Chulalongkorn Business School, Chulalongkorn University.

Athapol Ruangkanjanases is a faculty member at the Department of Commerce, Chulalongkorn Business School, Chulalonglorn University. He received his Ph.D. degree from Illinois Institute of Technology, USA. Before joining Chulalongkorn University, he taught at School of Management, Marist College, New York, USA. 